\title{
ANALISIS STRATEGI MARKETING DAN DAYA SAING ORGANISASI DI BALAI DIKLAT TAMBANG BAWAH TANAH
}

\author{
Hendris Agung Prasojo ${ }^{1)}$ Desrizal $^{2)}$ \\ ') Pusat Pengembangan Sumber Daya Manusia Aparatur KESDM \\ ${ }^{2)}$ Balai Diklat Tambah Tanah KESDM
}

\begin{abstract}
ABSTRAK
Organisasi Balai Diklat Tambang Bawah Tanah (BDTBT) yang bergerak di bidang jasa training membutuhkan strategi untuk mempertahankan keberlangsungan hidupnya. Persaingan antar organisasi juga semakin ketat di era sekarang ini. Kondisi ini mengharuskan sebuah organisasi memiliki strategi yang baik. BDTBT yang fokus pada tambang bawah tanah, membuat organisasi ini terbatas pangsa pasarnya. Tujuan penelitian ini adalah untuk mengetahui posisi BDTBT saat ini dan mendapatkan strategi organisasi yang dapat diimplementasikan dengan baik di BDTBT. Dalam upaya mendapatkan strategi yang baik, dibutuhkan metode yang mampu diterapkan secara baik diorganisasi ini. Pengumpulan data dilakukan melalui kuesioner. Pengolahan data dilakukan melalui proses input melalui matrik SWOT, kemudian evaluasi matrik internal faktor dan ekternal faktor. Dengan score Ifas dan Efas maka penentuan strategi yang harus dilakukan oleh BDTBT dapat dilakukan.
\end{abstract}

\section{Kata kunci: SWOT, Ifa dan Efa, Space Matrix}

\section{ABSTRACT}

The Organization of Underground Mining Training Center (BDTBT) which operates in the field of training services requires a strategy to maintain its survival. Competition between organizations is also getting tougher in this era. This condition requires an organization to have a good strategy. BDTBT which focuses on underground mining, makes this organization limited in its market share. The purpose of this study is to determine the current position of BDTBT and obtain organizational strategies that can be implemented properly in BDTBT. In an effort to get a good strategy, it takes a method that is able to be applied properly in this organization. Data collection was carried out through a questionnaire. Data processing is done through the input process through the SWOT matrix, then evaluation of the internal factor matrix and external factors. With Ifas and Efas scores, the determination of strategies that must be carried out by BDTBT can be done.

Key Words: SWOT, Ifa dan Efa, Space Matrix

\section{LATAR BELAKANG}

Balai Pendidikan dan Pelatihan Tambang Bawah Tanah (BDTBT) berkedudukan di Sawahlunto, Sumatera Barat. Sebagai Unit Pelaksana Teknis, BDTBT mempunyai tugas dan fungsi melaksanakan pendidikan dan pelatihan Tambang Bawah. BDTBT secara organisasi ada di bawah Pusat Pengembangan Sumber Daya Manusia Geologi Mineral dan Batubara

Penelitian ini melihat kondisi BDTBT dan menginventarisasi strategi pemasaran yang dapat diimplementasikan bagi organisasi BDTBT agar dapat meningkatkan daya saing di pasar yang ada. Hasil inventarisasi tersebut diidentifikasi secara ilmiah dengan menggunakan pendekatan internal factor analysis dan external factor analysis, sehingga dapat kesimpulan yang digunakan sebagai referensi penyusunan kebijakan yang berhubungan dengan pemilihan strategi marketing BDTBT. Pengembangan ini didasari pada faktafakta yang ada dan hasil kuesioner dari pegawai Balai Diklat Tambang Bawah Tanah. Fakta-fakta yang ada di BDTBT yaitu:

- Sebaran Peserta Pendidikan dan Pelatihan Balai Diklat Tambang Bawah Tanah yang tidak merata secara nasional.

- Kapasitas Sumberdaya Manusia yang meliputi widyaiswara, manajemen dan supporting staff masih membutuhkan peningkatan kompetensi.

- Sarana dan prasarana, standar kediklatan yang masih belum optimal pemanfaatannya.

- Kegiatan penelitian yang masih rendah padahal merupakan salah satu tupoksi widyaiswara.

Organisasi akan mengalami kondisi yang tidak tentu di masa depan demikian juga rencana strategis akan mengalami proses pembelajaran 
yang berkelanjutan pada tingkat konseptual dan elemen system organisasi akan terus berubah secara kualitatif.(Sanches \& Heena, 1997).

\section{IDENTIFIKASI MASALAH}

Penelitian ini bermaksud menjawab dua pertanyaan berikut:

- Bagaimana kondisi organisasi BDTBT saat ini dilihat dari faktor kekuatan dan kelemahan serta faktor peluang dan tantangan?

- Apa strategi pemasaran BDTBT yang sesuai dengan kondisi saat ini?

\section{TINJAUAN PUSTAKA}

\section{Strategi Pemasaran}

Setiap fase yang dikembangkan ada akibat yang muncul yaitu biaya yang timbul dari proses tersebut. Menurut Porter rantai nilai ini terdiri dari kegiatan primer dan kegiatan pendukung. Proses bisnis organisasi harus menjadi perhatian, adapun proses bisnis tersebut meliputi (Kotler dan Keller, 2009):

- Penginderaan pasar yaitu mencari informasi, mengolah dan menganalisisnya.

- Realisasi penawaran baru, yaitu meneliti, mengembangkan, dan menawarkan dengan cepat sesuai anggaran.

- Akuisisi pelanggan, mendefinisikan sasaran pasar dan pencarian pelanggan.

- Manajemen hubungan pelanggan yaitu kegiatan membangun pemahaman hubungan dan penawaran yang lebih mendalam.

- Manajemen pemenuhan yaitu kegiatan menyetujui dan memenuhi pesanan, pengiriman dan penagihan.

Pertanyaan pertanyaan kunci yang muncul pada kerangka perencanaan strategi pemasaran adalah bagaimana organisasi dapat mengidentifikasi peluang yang muncul, bagaimana organisasi dapat menciptakan penawaran nilai baru yang lebih efisien, bagaimana organisasi mampu menggunakan infrastruktur yang ada untuk menghantarkan nilai baru secara efiesien.

Mengekplorasi, menciptakan dan menghantarkan nilai organisasi dalam rangka memenuhi tuntutan pemasaran yang meliputi pemahaman terhadap nilai pelanggan, penciptaan nilai pelanggan, penghantaran nilai tersebut, menangkap nilai pelanggan, dan mempertahankan nilai pelanggan. Jika organisasi mampu melakukan tuntutan marketing tersebut, maka organisasi mampu bersaing secara unggul di pasaran. (Kotler $\&$ Keller, 2009).

Organisasi harus melakukan perencanaan pemasaran, yaitu: mengelola bisnis organisasi sebagai portofolio investasi, menilai kekuatan bisnis dan mempertimbangkan pertumbuhan pasar serta posisi organisasi, menyesuaikan dengan pasar yang ada dan menentukan strategi yang tepat. Rencana pemasaran organisasi bisa terbagi dalam beberapa tingkatan, tingkat korporat, divisi, unit bisnis bahkan unit produk.

Rencana strategi pemasaran merupakan rencana sentral yang digunakan menjadi instrument untuk mengkoordinasikan dan mengarahkan usaha pemasaran. Terbagi menjadi rencana yang menjelaskan tentang nilai jangka Panjang dan rencana yang lebih spesifik taktik pemasaran yaitu mengenai fitur, promosi, penyediaan produk, harga serta proses pendistribusian produk.

\section{SWOT}

Analisis SWOT banyak digunakan dalam penentuan strategi organisasi. Analisis SWOT pada penelitian ini digunakan untuk menganalisis strategi marketing yang cocok bagi BDTBT. Prinsip analisis ini mencakup peninjauan dan evaluasi yang dianggap sebagai kekuatan, kelemahan, peluang dan ancaman. (Rangkuti, 2011)

- Strength atau kekuatan merepesentasikan variabel variabel kekuatan yang dimiliki oleh organisasi secara internal.

- Weakness atau kelemahan merepresentasikan variabel variabel kelemahan yang dimiliki oleh organisasi.

- Opportunity atau peluang adalah karakteristik external yang oleh organisasi digunakan sebagai peluang keuntungan.

- Threats adalah karakteristik external yang mungkin punya potensi untuk menghambat atau menggagalkan organisasi.

Dalam analisis SWOT bisa dijelaskan dalam anatomi kuadran sebagai berikut:

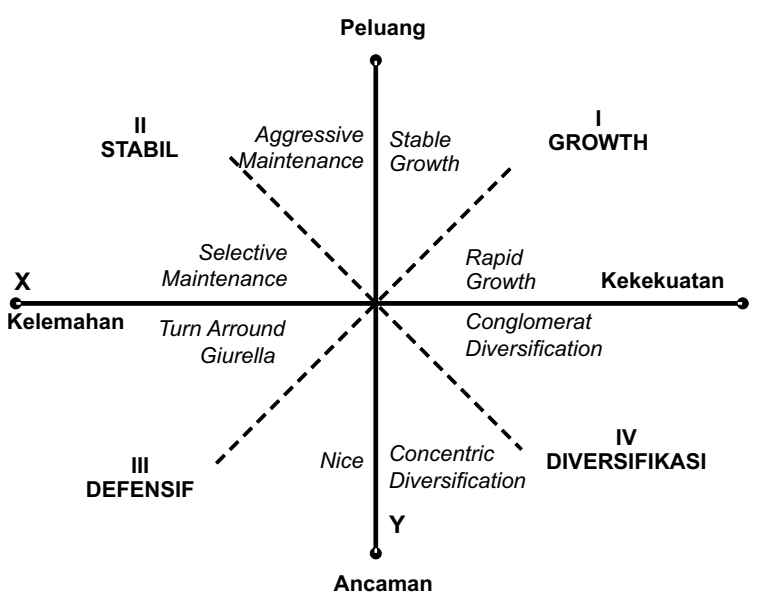


1) Kuadran I (Pengembangan dan Pertumbuhan) Pada kondisi kuadran I, pengembangan dan pertumbuhan secara agresif dimungkinkan. Organisasi memiliki kekuatan untuk memanfaatkan peluang peluang yang dimiliki. Untuk merebut pasar maka dapat dilakukan melalui alternatif alternatif yang memungkinkan, diantaranya yaitu:

- melalui penetrasi pasar, dengan meningkatkan jumlah produk serta pemasaran yang lebih agresif.

- Melalui pengembangan pasar, meningkatkan jumlah produk untuk meluaskan pasar yang ada.

- Melalui pengembangan produk yang ada melalui penyempurnaan atau dengan menciptakan produk produk yang baru.

2) Kuadran II ( Stabilisasi/rasionalisasi)

Pada kuadran ini, organisasi masih dimung- kinkan untuk berkembang asalkan mampu untuk melihat secara jeli dipasar mana organisasi akan bersaing.

3) Kuadran III (Defensif/Penciutan Kegiatan)

Pada kondisi kuadran III ini organisasi kemungkinan untuk berkembang sangat kecil karena kelemahannya begitu banyak. Hanya mampu untuk bertahan hidup, menjaga agar apa yang ada tidak hilang.

4) Kuadran IV (Diversifikasi)

Jika kondisi dengan produk yang ada sudah imun, sehingga perlu dilakukan pengembangan lebih lanjut dengan peluang peluang yang ada.

\section{BDTBT Kondisi Sekarang}

BDTBT sebagai lembaga pendidikan dan pelatihan telah menghasilkan jumlah alumni diklat seperti di grafik 1 .

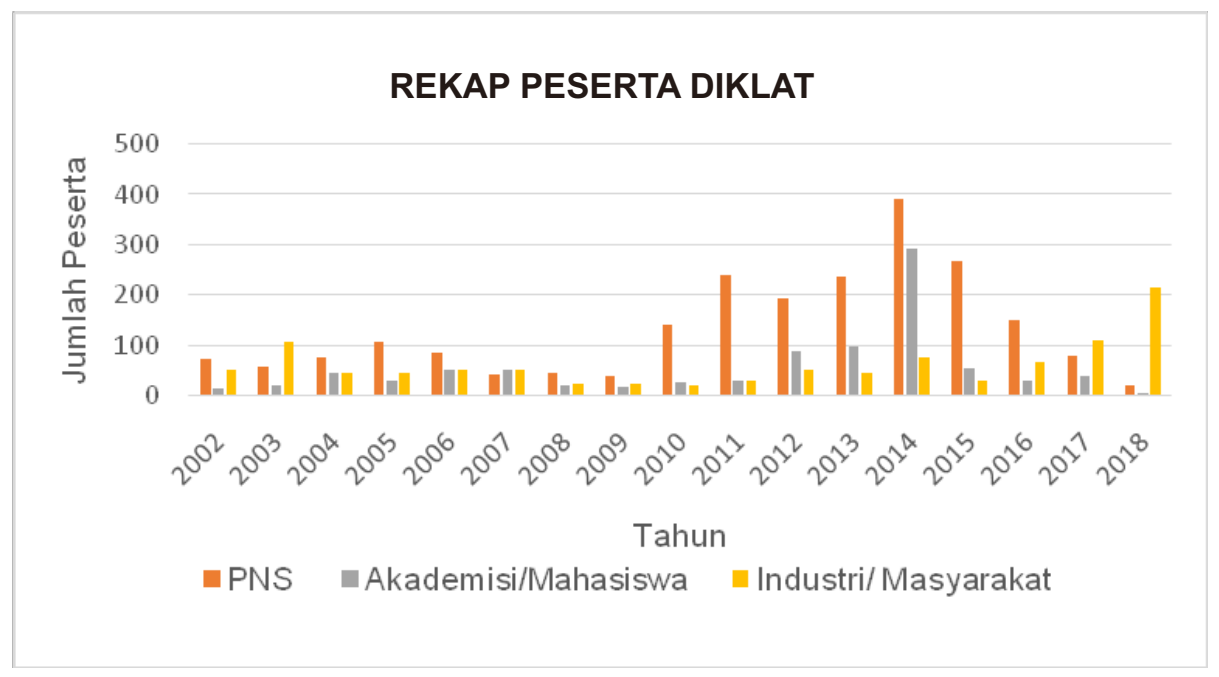

GRAFIK 1. Rekap peserta pelatihan BDTBT berdasar kriteria

Dari kurun waktu berdiri sampai dengan tahun 2018 terlihat perkembangan BDTBT yang fluktuatif. Terlihat dari gambar grafik 1 menunjukkan sampai dengan tahun 2016 peserta diklat yang melakukan pembelajaran di BDTBT didominasi oleh pegawai negeri sipil. Namun trend nya berubah dari tahun 2017 dan 2018 dimana didominasi oleh masyarakat dan industri. Hal ini disebabkan adanya kebijakan harus mendiklatkan masyarakat. Sehingga BDTBT menjalankan kebijakan tersebut, sebagai institusi pemerintah BDTBT tetap meningkatkan kompetensi ASN di kementerian ESDM sehingga tidak terjadi ketimpangan baik jumlah maupun kualitas. Hal ini disebabkan karena kompetensi organisasi Kementerian ESDM harus terus dikembangkan sebagai bentuk knowledge management.
Dari fakta dan data baik primer maupun sekunder penelitian ini membahas tentang daya saing BDTBT di ranah industri pelatihan yang akan bersaing dengan provider-provider swasta yang berkembang di Indonesia. Sehingga BDTBT mampu memberikan arah kebijakan strateginya. Identifikasi konsisi BDTBT saat ini menggunakan analisisi kondisi internal dan external sehingga akan menghasilkan posisi BDTBT, kemudian dapat dilakukan strategy yang sesuai dengan faktor faktor yang mempengaruhi kondisi BDTBT tersebut.

Fakta-fakta yang terjadi berdasar pada data primer dan sekunder dapat di lihat sebagai berikut:

- Sebaran asal peserta diklat belum menyeluruh dari wilayah Indonesia.

- Pasar terbatas yang merupakan niche market 


\section{Internal dan Eksternal Faktor}

Menurut Kotler dan Keller 2009 ada dua faktor yang mempengaruhi keputusan konsumen dalam mengikuti pelatihan di BDTBT, yaitu faktor internal dan faktor external:

Faktor internal yang mempengaruhi pasar BDTBT yaitu

- Tingkat competitiveness harga produk/servis yang ditawarkan ke pasar

- Jaminan kualitas produk/servis yang ditawarkan ke pasar

- Kerjasama institusi dengan pihak lain

- Pelayanan yang diberikan kepada pelanggan

- Tingkat keunikan produk/servis yang ditawarkan

- Tingkat ketersediaan sarana dan prasarana

- Tingkat kompetensi SDM pengajar

- Kompetensi supporting staff terkait program produk/servis di institusi

- Daya saing produk/servis yang di tawarkan ke pasar

- Tingkat promosi produk/servis yang sudah dilakukan organisasi

Faktor eksternal yang mempengaruhi yaitu:

- Kemampuan BDTBT menangkap pasar
- Tingkat pemanfaatan kerjasama institusi dengan pihak lain

- Tingkat loyalitas klien terhadap layanan produk/servis dari institusi

- Branding institusi di pangsa pasar

- Tingkat permintaan pasar terhadap produk/ servis yang ditawarkan ke pasar

- Kondisi persaingan usaha yang dihadapi

- Resiko keberlangsungan produk/servis organisasi

- Inovasi produk/servis pesaing di pangsa pasar

- Kebijakan pemerintah terhadap usaha unit organisasi

- Tingkat imunitas atau kejenuhan pasar terhadap produk/servis yang ditawarkan

- Tingkat perubahan kondisi ekonomi dan sosial konsumen

\section{DESKRIPSI KERANGKA BERFIKIR}

Proses penelitian ini, menggunakan kerangka berfikir untuk mengetahui kondisi nyata yang terjadi di BDTBT, melalui analisis faktor internal dan external sebagai input stage, kemudian dilakukan matsching stage dan decision stage sebagai rekomendasi bagi pengambil keputusan di BDTBT.

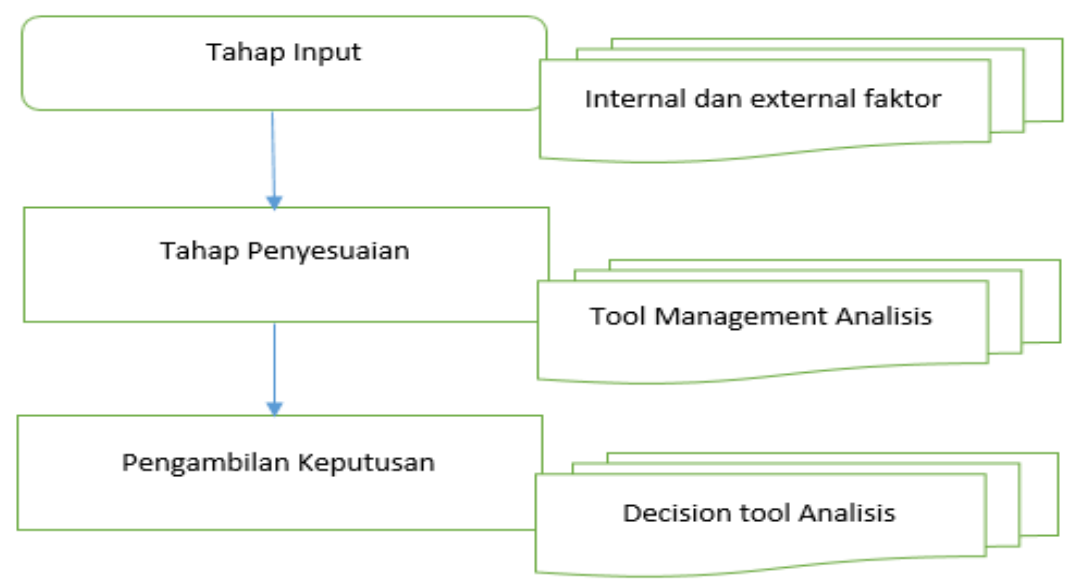

Bagan1. Kerangka Fikir Penelitian

\section{PEMBAHASAN}

\section{Responden}

Responden merupakan pegawai tetap BDTBT yang terdiri dari staff, manajemen dan tenaga fungsional.

Grafik 2 menunjukkan responden sebagian besar sudah bekerja di Balai Diklat Tambang Bawah Tanah sekitar satu sampai dengan lima tahun. Seperempat dari responden sudah bekerja di organisasi lebih dari sepuluh tahun. Selebihnya adalah responden dengan masa kerja antara enam sampai dengan sepuluh tahun. Artinya dengan data tersebut responden sudah memahami dan menyadari kondisi BDTBT secara menyeluruh.

\section{Proses Input \\ a. BDTBTSWOT}

SWOT analisis eksternal; didasarkan pada diamond porter yang meliputi (Porter dalam Thompson.et all, 2016):

- Industri sejenis yang baru masuk.

- Rival atau pesaing

- Product pengganti

- Posisi tawar dari pembeli 


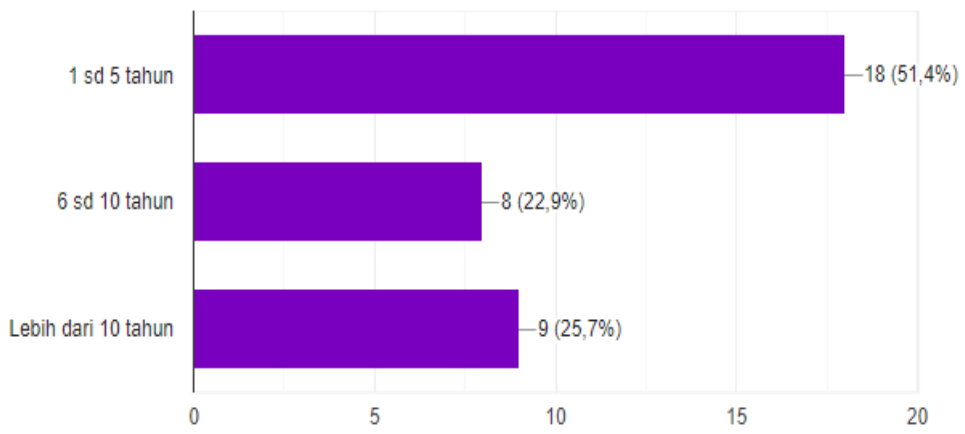

Grafik 2. Data Responden Pegawai BDTBT (Bezeting Pegawai 2019)

- Posisi tawar dari para suplier

Analisis internal didasarkan pada konsep strategi marketing untuk industri jasa yang meliputi 7P yaitu product, price, place, promotion, people, process dan physical evidence.

Hasil dari proses pengumpulan data kepada responden di organisasi Balai Diklat Tambang Bawah Tanah, dapat dilihat dari tabel 1.

\section{Tabel 1. Data SWOT BDTBT}

\begin{tabular}{|c|c|c|c|c|c|}
\hline \multicolumn{6}{|c|}{ SWOT BDTBT } \\
\hline STRENGTH & Total & Avg & Rtg & Integrity & Score \\
\hline $\begin{array}{l}\text { 1. Tingkat competitiveness harga produk/servis yang } \\
\text { ditawarkan ke pasar }\end{array}$ & 98 & 2,8 & 3 & 1,8 & 5,4 \\
\hline $\begin{array}{l}\text { 2. Respon klien terhadap kualitas produk organisasi } \\
\text { yang ditawarkan }\end{array}$ & 94 & 2,685714286 & 3 & 1,6 & 4,8 \\
\hline $\begin{array}{l}\text { 3. Jaminan kualitas produk/servis yang ditawarkan ke } \\
\text { pasar }\end{array}$ & 102 & 2,914285714 & 3 & 1,8 & 5,4 \\
\hline 4. Kerjasama institusi dengan pihak lain & 96 & 2,742857143 & 3 & 1,4 & 4,2 \\
\hline 5. Pelayanan yang diberikan kepada pelanggan & 105 & 3 & 3 & 1,6 & 4,8 \\
\hline \multirow[t]{2}{*}{ 6. Tingkat keunikan produk/servis yang ditawarkan } & 103 & 2,942857143 & 3 & 1,8 & 5,4 \\
\hline & TOTAL & & & $\underline{10}$ & 30 \\
\hline \multicolumn{6}{|l|}{ Weaknes } \\
\hline 1. Tingkat ketersediaan sarana dan prasarana & 125 & 3,571428571 & 4 & 2,4 & 9,6 \\
\hline 2. Tingkat kompetensi SDM pengajar & 104 & 2,971428571 & 3 & 1,6 & 4,8 \\
\hline $\begin{array}{l}\text { 3. Kompetensi supporting staff terkait program } \\
\text { produk/servis di institusi }\end{array}$ & 100 & 2,857142857 & 3 & 1,6 & 4,8 \\
\hline 4. Ketercapaian pemasaran produk/servis di pasar & 80 & 2,285714286 & 2 & 1,2 & 2,4 \\
\hline 5. Daya saing produk/servis yang ditawarkan ke pasar & 96 & 2,742857143 & 3 & 1,4 & 4,2 \\
\hline \multirow{2}{*}{$\begin{array}{l}\text { 6. Tingkat promosi produk/servis yang sudah } \\
\text { dilakukan organisasi }\end{array}$} & 89 & 2,542857143 & 3 & 1,8 & 5,4 \\
\hline & TOTAL & & & $\underline{10}$ & 31,2 \\
\hline Opportunity & Total & Average & Rating & Integrity & Score \\
\hline 1. Kemampuan organisasi menangkap pasar & 84 & 2,4 & 2 & 1,6 & 3,2 \\
\hline 2. Jalinan institusi dengan klien & 88 & 2,514285714 & 3 & 1,6 & 4,8 \\
\hline $\begin{array}{l}\text { 3. Dampak dari keragaman produk/servis yang } \\
\text { ditawarkan ke pasar }\end{array}$ & 87 & 2,485714286 & 2 & 1,6 & 3,2 \\
\hline $\begin{array}{l}\text { 4. Tingkat pemanfaatan kerjasama institusi dengan } \\
\text { pihak lain }\end{array}$ & 93 & 2,657142857 & 3 & 1,4 & 4,2 \\
\hline $\begin{array}{l}\text { 5. Tingkat loyalitas klien terhadap layanan } \\
\text { produk/servis dari institusi }\end{array}$ & 89 & 2,542857143 & 3 & 1 & 3 \\
\hline 6. Branding institusi di pangsa pasar & 87 & 2,485714286 & 2 & 1,6 & 3,2 \\
\hline \multirow[t]{2}{*}{$\begin{array}{l}\text { 7. Tingkat permintaan pasar terhadap produk/servis } \\
\text { yang ditawarkan ke pasar }\end{array}$} & 89 & 2,542857143 & 3 & 1,2 & 3,6 \\
\hline & TOTAL & & & $\underline{10}$ & 25,2 \\
\hline
\end{tabular}




\begin{tabular}{|l|l|l|l|l|l|}
\hline Threat & & & & & \\
\hline 1. Kondisi persaingan usaha yang dihadapi & 119 & 3,4 & 3 & 2,4 & 7,2 \\
\hline 2. Resiko keberlangsungan produk /servis organisasi & 96 & 2,742857143 & 3 & 1,2 & 3,6 \\
\hline 3. Inovasi produk/servis pesaing di pangsa pasar & 91 & 2,6 & 3 & 1,2 & 3,6 \\
\hline $\begin{array}{l}\text { 4. Kebijakan pemerintah terhadap usaha unit } \\
\text { organisasi }\end{array}$ & 80 & 2,285714286 & 2 & 1,8 & 3,6 \\
\hline $\begin{array}{l}\text { 5. Tingkat imunitas atau kejenuhan pasar terhadap } \\
\text { produk/servis yang ditawarkan }\end{array}$ & 105 & 3 & 3 & 1,6 & 4,8 \\
\hline $\begin{array}{l}\text { 6. Tingkat perubahan kondisi ekonomi dan sosial } \\
\text { konsumen }\end{array}$ & 98 & 2,8 & 3 & 1,8 & 5,4 \\
\hline & TOTAL & & & 10 & 28,2 \\
\hline
\end{tabular}

Tabel 1 diatas mengindikasikan secara internal masih terdapat kelemahan yang harus diperbaiki, meski disisi kekuatan BDTBT memiliki kekuatan yang baik. Berdasar hasil analisis, respon klien BDTBT terhadap produk yang ditawarkan masih relatif rendah sehingga membutuhkan peningkatan pelayanan yang lebih baik. Termasuk inisiatif bekerjasama dengan institusi lain juga perlu ditingkatkan, karena dengan program kerjasama akan membuka banyak peluang yang bisa digunaka oleh BDTBT untuk membuka pasar yang lebih luas.

Tingkat promosi yang sudah dilakukan oleh BDTBT dan ketercapaian BDTBT dalam merebut pasar juga masih rendah, hal ini dipengaruhi oleh beberapa faktor yang diantaranya bahwa BDTBT bukan unit badan layanan umum dan masih menggunakan anggaran yang sifatnya Anggaran Pendapatan Belanja Negara (APBN). Peningkatan kemampuan tersebut dapat meningkatkan branding BDTBT di mata klien atau stake holder. Kondisi ini seiring dengan BDTBT dalam merebut peluang melalui pasar yang ada juga masih rendah. Rebranding BDTBT perlu ditingkatkan sehingga masyarakat lebih mengenal tentang organisasi BTBT. Tantangan yang dirasa cukup besar bagi organisasi ini adalah kebijakan pemerintah yang dirasa belum berpihak kepada organisasi berdasar dari analisa data dari responden.

\section{b. TOWS Matrix}

Proses pemilihan strategy berdasar data diatas dapat dilakukan pengelaborasian antara S-O, S-T, W-O, dan W-T yang sering kita kenal sebagai TOWS matrik (Rangkuti, 2011).

S-O adanya kekuatan dan peluang yang ada sehingga strategi yang digunakan adalah menggunakan semua kekuatan untuk merebut peluang.

W-O strategy yang disusun dengan cara meminimalkan kelemahan untuk memanfaatkan peluang yang ada.

S-T strategy yang disusun dengan menggunakan semua kekuatan untuk mengatasi ancaman yang ada.

W-T strategy yang disusun dengan cara meminimalkan kelemahan untuk menghindari ancaman yang ada.

Tabel 2. Strategi S-O

\begin{tabular}{|l|l|}
\hline \multicolumn{1}{|c|}{ S } & \multicolumn{1}{c|}{ O } \\
\hline - Tingkat competitiveness harga produk/servis & - Kemampuan organisasi menangkap pasar \\
yang ditawarkan ke pasar & - Jalinan institusi dengan klien \\
- Respon klien terhadap kualitas produk & - Dampak dari keragaman produk/servis yang \\
organisasi yang ditawarkan & ditawarkan ke pasar \\
- Jaminan kualitas produk/servis yang & - Tingkat pemanfaatan kerjasama institusi \\
ditawarkan ke pasar & dengan pihak lain \\
- Kerjasama institusi dengan pihak lain & - Tingkat loyalitas klien terhadap layanan \\
- Pelayanan yang diberikan kepada pelanggan & produk/servis dari institusi \\
- Tingkat keunikan produk/servis yang & - Branding institusi di pangsa pasar \\
ditawarkan & - Tingkat permintaan pasar terhadap \\
& produk/servis yang ditawarkan ke pasar \\
& \\
&
\end{tabular}

\section{Strategy}

- BDTBT harus mampu merebut pasar melalui pengaturan harga yang ditawarkan sesuai market demand. 
- Meningkatkan kualitas produk servis yang ditawarkan melalui penguatan di area input, proses dan output yang dihasilkan.

- Kerjasama dengan institusi lain untuk menjaga pasar dan juga branding organisasi.

- Merebut pasar dengan meningkatakan pelayanan kepada pelanggan secara baik dan continous improvement.

\begin{tabular}{|l|l|}
\hline \multicolumn{1}{|c|}{ W } & \multicolumn{1}{c|}{ O } \\
\hline - Tingkat ketersediaan sarana dan prasarana & - Kemampuan organisasi menangkap pasar \\
- Tingkat kompetensi SDM pengajar & - Jalinan institusi dengan klien \\
- Kompetensi supporting staff terkait program & - Dampak dari keragaman produk/servis yang \\
produk/servis di institusi & ditawarkan ke pasar \\
- Ketercapaian pemasaran produk/servis di & - Tingkat pemanfaatan kerjasama institusi dengan \\
pasar & pihak lain \\
- Daya saing produk/servis yang di tawarkan & - Tingkat loyalitas klien terhadap layanan \\
ke pasar & produk/servis dari institusi \\
- Tingkat promosi produk/servis yang sudah & - Branding institusi di pangsa pasar \\
dilakukan organisasi & - Tingkat permintaan pasar terhadap \\
& produk/servis yang ditawarkan ke pasar \\
& \\
\hline
\end{tabular}

\section{Strategy}

- Tingkat kompetensi SDM internal harus terus ditingkatkan sehingga branding institusi meningkat.

- Daya saing produk terus ditingkatkan sehingga tingkat permintaan pasar terhadap produk dan servis yang ditawarkan juga meningkat secara signifikan.

- Promosi terus dilakukan dengan menggunakan berbagi media promosi seperti digital marketing dengan mengguanakan berbagai media sosial atau dengan metode integrated marketing communication sehingga dapat menembus pasar yang ada.

\begin{tabular}{|c|c|}
\hline $\mathbf{S}$ & $\mathbf{T}$ \\
\hline $\begin{array}{l}\text { - Tingkat competitiveness harga produk/servis } \\
\text { yang ditawarkan ke pasar } \\
\text { - Respon klien terhadap kualitas produk } \\
\text { organisasi yang ditawarkan } \\
\text { - Jaminan kualitas produk/servis yang } \\
\text { ditawarkan ke pasar } \\
\text { - Kerjasama institusi dengan pihak lain } \\
\text { - Pelayanan yang diberikan kepada pelanggan } \\
\text { - Tingkat keunikan produk/servis yang } \\
\text { ditawarkan }\end{array}$ & $\begin{array}{l}\text { - Kondisi persaingan usaha yang dihadapi } \\
\text { - Resiko keberlangsungan produk /servis } \\
\text { organisasi } \\
\text { - Inovasi produk/servis pesaing di pangsa pasar } \\
\text { - Kebijakan pemerintah terhadap usaha unit } \\
\text { organisasi } \\
\text { - Tingkat imunitas atau kejenuhan pasar terhadap } \\
\text { produk/servis yang ditawarkan } \\
\text { - Tingkat perubahan kondisi ekonomi dan social } \\
\text { konsumen }\end{array}$ \\
\hline \multicolumn{2}{|c|}{$\begin{array}{l}\text { Strategy } \\
\text { - Kondisi persaingan yang semakin ketat dengan banyaknya kompetitor dari berbagai lembaga } \\
\text { pelatihan sehingga produk yang ditawarkan kepasar harus mampu bersaing baik secara harga } \\
\text { maupun kualitas. } \\
\text { - Inovasi terhadap jenis layanan harus terus di lakukan karena produk lain juga terus melakukan } \\
\text { inovasi, keunikan produk juga terus di perbaiki. } \\
\text { - Pasar yang makin imun juga harus di siasati melalui peningkatan pelayanan kepada pelanggan. }\end{array}$} \\
\hline
\end{tabular}




\begin{tabular}{|l|l|}
\hline \multicolumn{1}{|c|}{ W } & \multicolumn{1}{c|}{ T } \\
\hline - Tingkat ketersediaan sarana dan prasarana & - Kondisi persaingan usaha yang dihadapi \\
- Tingkat kompetensi SDM pengajar & - Resiko keberlangsungan produk /servis \\
- Kompetensi supporting staff terkait program & organisasi \\
produk/servis di institusi & - Inovasi produk/servis pesaing di pangsa pasar \\
- Ketercapaian pemasaran produk/servis di & - Kebijakan pemerintah terhadap usaha unit \\
pasar & organisasi \\
- Daya saing produk/servis yang di tawarkan & - Tingkat imunitas atau kejenuhan pasar terhadap \\
kepasar & produk/servis yang ditawarkan \\
- Tingkat promosi produk/servis yang sudah & - Tingkat perubahan kondisi ekonomi dan sosial \\
dilakukan organisasi & konsumen \\
\hline \multicolumn{2}{|l}{ Strategy } \\
- Sarana prasarana yang masih kurang ditingkatkan agar mampu bersaing dengan kompetitor. \\
- Tingkat kompetensi SDM ditingkatkan agar mampu menghadapi perubahan kondisi ekonomi. \\
- Rendahnya pemasaran juga diminalisir dengan melakukan inovasi inovasi dibidang pemasaran. \\
\hline
\end{tabular}

\section{Proses Penyesuaian}

a. Ifa dan Efa Score

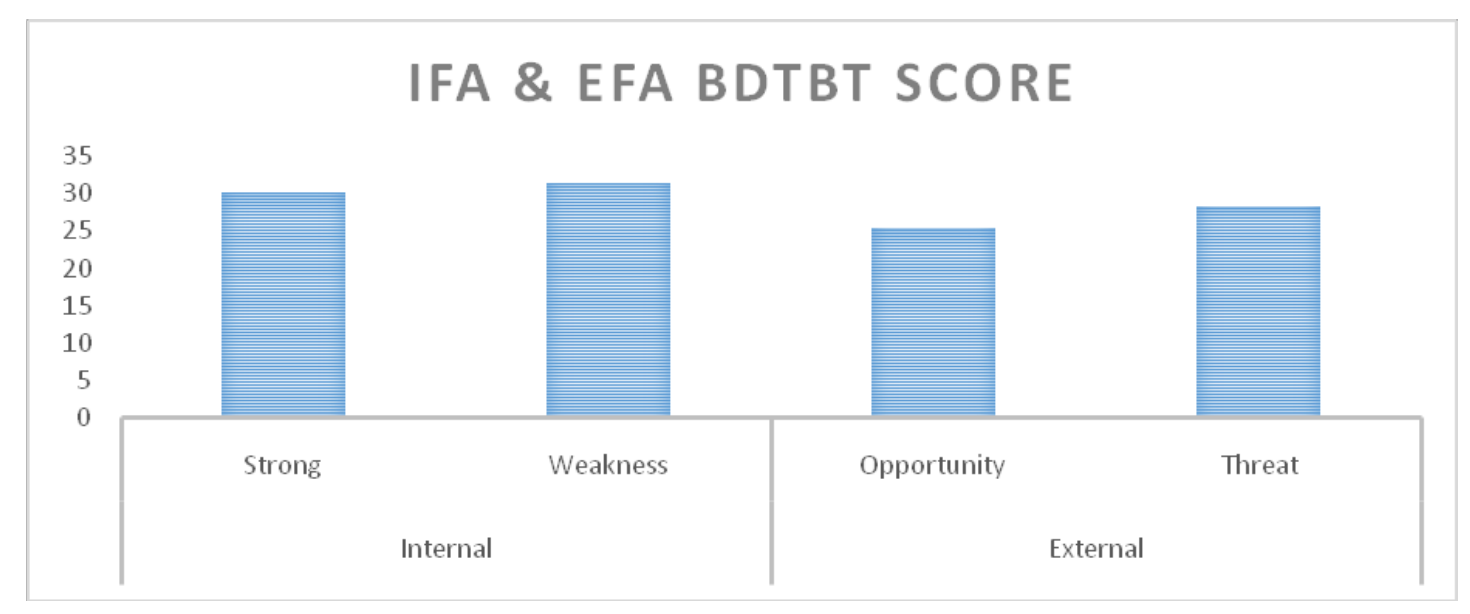

Grafik 3. Score Ifa dan Efa BDTBT

Ifa BDTBT didasarkan pada hasil analisis faktor internal, score yang didapat yaitu 30 dan 31,2 sedangkan Efa berdasar analisis faktor eksternal dengan score 25,2 dan 28,2. Kondisi internal menunjukan dibutuhkannya penguatan yang terus menerus karena kondisi kelemahan BDTBT secara score lebih besar. Demikian juga untuk score faktor eksternal, peluang lebih kecil dari pada ancaman, sehingga dibutuhkan strategi untuk meningkatkan peluang secara lebih baik.

Posisi BDTBT saat ini adalah berada pada kuadran 3 dimana strategi yang dapat dilakukan oleh BDTBT adalah strategi defensif seperti terlihat di Gambar 2. Strategi yang dapat dilakukan oleh BDTBT strategi untuk mempertahankan posisi seperti sekarang ini. Beberapa strategi defensif yang dilakukan oleh berbagai industri setelah mengetahui kondisinya yaitu sebagai berikut: 


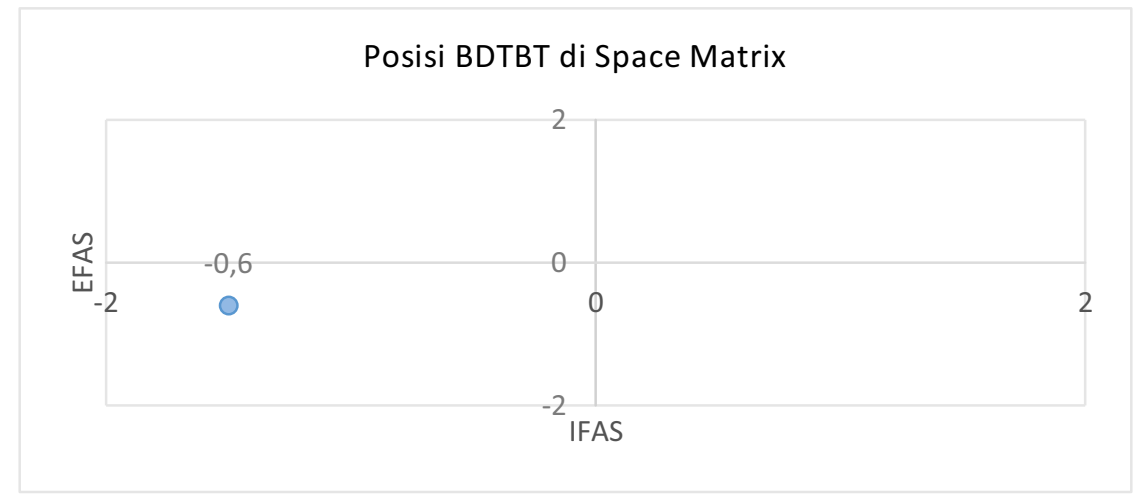

Gambar 2. Space Matrix Posisi BDTBT

a) Penghematan

Penghematan dilakukan oleh organisasi melalui pemotongan biaya melalui pelepasan aset yang membutuhkan biaya yang dapat mengurangi keuntungan, strategi ini sering disebut turn arround atau reorganisasi. Aset aset yang tidak produktif di non aktifkan atau aset produktif di non aktifkan jika kondisi perusahaan mengalami penurunan profit yang signifikan. Bentuk pemotongan aset ini biasanya berupa penutupan salah satu unit bisnis, pengurangan pegawai dan juga sistem kendali biaya secara ketat.

b) Strategi divestasi

Strategi ini dilakukan jika penghematan gagal, membutuhkan sumber daya lebih, ada bagian yang tidak sejalan dengan organisasi. Divestasi ini melakukan pemisahan unit bisnis atau melepas salah satu unit bisnis yang ada untuk mendapatkan tambahan modal.

c) Likuidasi

Aset bisnis yang tidak produktif dihentikan atau dilikuidasi, melakukan strategi ini memiliki konsekuensi secara emosional tetapi biasanya akan dilakukan jika kondisi organisasi terus merugi.Strategi likuidasi dilakukan jika strategi penghematan dan dan strategi divestasi tidak berhasil.

\section{Proses Pengambilan Keputusan}

Posisi BDTBT saat ini ada di point (-1,5 dan $0,6)$, artinya posisi BDTBT ada di kuadran tiga. Dengan score Efas negatif 1,5 artinya penerimaan pasar BDTBT cukup rendah, diperlukan usaha yang cukup besar agar BDTBT bisa lebih diterima pasar eksternal. Score Ifas BDTBT juga relatif rendah yaitu minus 0,6 artiny penguatan secara internal harus dilakukan baik sumber daya manusia maupun sarana prasarananya. BDTBT saat ini merupakan institusi pemerintah yang harus mensupport unit diatasnya yang merupakan Badan Layanan Umum. Berbeda dengan institusi swasta yang goalnya adalah profit, namun BDTBT harus menjaga customer atau stake holdernya. Strategi defensif di Industri swasta adalah untuk mempertahankan profit, namun di BDTBT strategi defensif merupakan usaha untuk mempetahankan pelanggan atau keluarnya pelanggan dari pasar BDBT. Strategy defensif bagi BDTBT juga berfungsi untuk memanjangkkan umur pelanggan atau kita kenal dengan customer retention.

\section{KESIMPULAN}

Berdasar analisis data dan kondisi BDTBT yang dipengaruhi oleh faktor internal dan external, posisi saat ini BDTBT ada di kuadran tiga, maka pilihan strategi yang dapat dilakukan adalah strategi defensif. Strategi defensif yang memungkinkan untuk dilakukan bagi BDTBT ada dua yaitu:

a. BDTBT berusaha membuat pelanggan ketergantungan terhadap BDTBT sehingga pelanggan akan merasa rugi, enggan jika berpindah dari layanan BDTBT. BDTBT dapat melakukan inovasi dari sisi harga layanan melalu pemotongan tarif, atau melakukan hubungan emosional lainnya dengan pelanggan sehingga terjalin hubungan yang baik dan harmonis antara BDTBT dengan pelanggan. Pada dasarnya BDTBT melakukan mutualisme customer relationship.

b. BDTBT meningkatkan customer satisfaction, dalam memberikan pelayanan jasa nya BDTBT terus melakukan continous improvement dibidang pelayanan, sehingga tidak mudah tergantikan oleh pesaing yang rata rata adalah provider training swasta. Menurut Thjiptono Strategi Pemasaran ada beberapa strategi yang dapat dilakukan untuk meningkatkan kepuasan pelanggan yaitu: 
- Melalui strategi marketing menjalin hubungan baik dengan marketing.

- Strategy superior customer service

- Strategy unconditional guarantees

- Penanganan keluhan pelanggan secara optimal dan efisien

- Meningkatkan kinerja organisasi dari segala lini.

\section{REKOMENDASI}

Perlu ada pertimbangan secara makro dari segi politik dan ekonomi, sosial, teknologi dan legal terhadap keberlangsungan BDTBT sehingga tidak semata mata hasil kajian secara akademik untuk menentukan strategi yang akan diambil oleh manajemen BDTBT. Kebijakan yang diambil harus melihat tingkat manfaat yang lebih besar bagi organisasi dan stake holdernya.

Kerjasama dengan institusi lain untuk menjaga pasar dan juga branding organisasi harus terus dilakukan dengan memanfaatkan berbagai media agar dapat merebut pasar, meningkatakan pelayanan kepada pelanggan secara baik dan continous improvement.

Secara khusus BDTBT dapat meningkatkan penguatan secara internal, menghilangkan atau mengurangi berbagai kelemahan yang ada, misalnya; meningkatkan kompetensi SDM agar mampu menghadapi perubahan kondisi pasar, melakukan inovasi inovasi dibidang pemasaran.

\section{DAFTAR PUSTAKA \\ Buku}

Keller, P. K. (2009). Marketing Management.

Kotler dan Keller, 2. (2009).

Rangkuti, F. (2011). SWOT Balanced Scorecard. Journal

Florencia, Z. S. (n.d.). Analisa faktor internal dan faktor eksternal yang mempengaruhi konsumen dalam melakukan keputusan pemebelian makanna di restoran fastfood Surabaya.
GÜLLÜ, K. (2018). A SWOT Analysis To Determine The Tourism Potential of The Develi As A Tourism Destination. Business \& Management Studies: An International Journal, 6(4).

Koupaei, M. N. (2015). A Fuzzy ANP-SWOT approach for analyzing the IT problems based on capabilities in Iran. International Journal of Supply and Operations Management.

Kumar, A. S. (2018). Analyzing indian research and development organizations: A SWOT analysis. nternational Journal of Innovation Science, 10(3), 298-315.

Maulina, E. \&. (2018). SWOT analysis for business strategies: A case of virage awi in the bamboo craft industries, bandung, indonesia. Review of Integrative Business and Economics Research, 7.

N, A. (2019). A swot analysis to evaluate market potential of Pinarbasi Destination. Business \& Management Studies: An International Journal, 7(2), , 856-876.

Rivani, R. S. (2018). SWOT analysis on the export-oriented ceramic industry centre in purwakarta, indonesia. Review of Integrative Business and Economics Research, 7.

Sanches \& Heena, 1. (1997).

Thompson, P. G. (2016). Crafting \& Executing Strategy. Mc Graw Hill.

Tjoe, T. F. (2010). Strategi Bisnis Pada PT. CTL dengan Pendekatan Metode TOWS. BINUS BUSINESS REVIEW Vol.1 No.2 November 2010: 434-447.

Woźniak, J. \&. (2018). Logistic organization of mass events in the light of SWOT analysis case study. TEM Journal,.

Yadi, H. (2014). Penerapan Analisis SWOT di Manajemen Pemasarana Bisnis Developer. Jom FISIP Volume 1 No. 2 -Oktober 2014.

BDTBT (2019) . Bezeting Pegawai Balai Diklat Tambang Bawah Tanah 2019. 